\title{
La péripneumonie bovine Précisions sur une nouvelle voie d'immunisation Résultats - Conséquences et hypothèses
}

\author{
par J. ORUE ef G. MÉMERY
}

\section{CONSIDÉRATIONS GÉNÉRALES}

WILLEMS (1), dans une expérience «princeps» démontre, dès 1852, que l'inoculation souscutanée de lymphe péripneumonique provoque l'apparition d'engorgements plus ou moins importants, qui entraînent souvent la mort de l'animal dans un délai variable.

Cette forme expérimentale de la maladie, bien qu'elle soit accompagnée d'une dissémination du virus dans l'organisme, mise en évidence notamment par les travaux de HALL NORMAN ef BEATON (1931) (2), de TURNER, CAMPBELL ef DICK (1935) (3), confirmés par P. MORNET, J. ORUE et D. LAMINE (4), ne peut reproduire la maladie sous sa forme naturelle sans l'emploi d'artifices plus ou moins ingénieux mais inconstants dans leurs effets.

Ce phénomène est la conséquence inévitable de l'inoculation de lymphe péripneumonique ou de culture virulente dans le tissu conjonctif souscutané, quelle que soit la région choisie. II apparaît, en général, du $6^{\mathbf{e}}$ au $10^{\mathrm{e}}$ jour après l'inoculation et se manifeste par un épaississement cutané très sensible à la palpation. Un placard. non dépressible, adhérant au tissu sous-jacent, se développe ensuite, puis s'étend rapidement et s'accompagne, en fin d'évolution, d'œè̀mes plus ou moins volumineux dar.s les parties déclives.

Cette tumeur caractéristique ne doit pas être confondue avec une réaction que noss avons observée fréquemment et que nous considérons comme une réaction d'immunité. D'origine certainement allergique, elle apparaît, souvent

Reçu pour publication : juin 1960.

Rev. Elev. Méd. vét. Pays trop., 1960, 13, no 2-3. dans les heures qui suivent l'inoculation virulente ou vaccinale, sur certains animaux qui se révèlent ultérieurement totalement immunisés. Précoce et fugace, elle disparaît entre la $24^{\mathrm{e}}$ et la 48 e heure, se caractérise par un œdème de consistance molle, dépressible, de faible importance mais pouvant, parfois, atteindre la largeur de la main.

WILLEMS (1) est le premier à démontrer que l'animal guéri bénéficie d'une immunité solide et durable. Cependant les pertes résultant des inoculations virulentes sont importantes, car la réaction locale qui en résulte est toujours suivie de répercussions graves sur l'organisme. Elles se manifestent :

- par des lésions ganglionnaires (adénites, congestion, foyers de nécrose) ;

— par des lésions de « voisinage » (pleurales, péricardiques, péritonéales), conséquence de l'infiltration de la sérosité à travers les plans musculaires ;

- par des lésions rénales fréquentes (10 p. 100 des cas) (néphrite épithéliale) :

- par une leucopénie progressive ;

- par un amaigrissement subit, rapide, proche de la cachexie qui apparaît dans la phase terminale, même lorsque l'issue de la réaction est favorable.

Au cours de ces expériences, WILLEMS (1) consiate que le phénomène local et ses conséquences sont nettement moins spectaculaires et moins graves lorsque l'inoculation est effectuée dans certaines régions : extrémités des membres et de la queue. L'immunité conférée n'en est pas moins solide.

De ces observations est née la méthode d'immunisation willemsienne qui en réalité ne fait que 
confirmer la valeur des procédés empiriques utilisés depuis des temps immémoriaux par les éleveurs nomades africains. Elle sert de base à la prophylaxie médicale de la péripneumonie bovine, en Europe, jusqu'au début du XXe siècle.

A la suite de ces résultats, de multiples techniques d'inoculation et de nombreux procédés de vaccination ont été proposés pour obtenir une innocuité optima, tout en conservant l'efficacité reconnue à cette méthode infectante.

II serait fastidieux de rappeler tous les travaux publiés sur ce sujet, mais on peut admettre que les recherches se sont orientées principalement dans deux directions:

- recherche d'une voie d'inoculation peu propice au développement des œè̀mes réactionnels ;

- recherche de l'immunité par. l'atténuation du pouvoir pathogène du micro-organisme.

En ce qui concerne les différentes voies d'inoculation envisagées, il ne semble pas que l'on puisse parler de recherches proprement dites, mais plutôt d'observations faites à l'occasion du contrôle des réactions vaccinales.

Elles permettent de définir les règles qui président au choix des lieux d'inoculation les plus favorables. Très tôt, on admet que le conjonctif sous-cutané lâche favorise un développement excessif des tumeurs péripneumoniques (encolure, tronc, fanon), tandis que les régions à tissu conjonctif dense et peu abondant (extrémités des membres, de la queue, chanfrein), réduisent considérablement les risques consécutifs à l'inoculation virulente.

Au contraire, les recherches sur l'atténuation de la virulence de Mycoplasma mycoides ont suscité de très nombreux travaux portant principalement :

- sur la diminution du pouvoir pathogène de la lymphe primaire ou secondaire par l'action des antiseptiques et bactériostatiques (acide phénique, glycérine, formol à 4 p. 1.000, selon CURASSON et HANRAS (1932) (5) et MENDES 1958) (6) ;

- sur l'obtention après l'isolement et la culfure du micro-organisme par NOCARD ef ROUX (1895), de virus-vaccin, par cultures atténuées en bouillon Martin-sérum suivant la technique de WALKER (1921) (7-8), par culture sur œufs embryonnés mises au point par SHFRIFF et PIERCY (9) ef PIERCY et KNIGHT (10-11).
Quelles que soient les voies d'inoculation préconisées jusqu'à ce jour et la méthode d'atténuation utilisée, il est admis maintenant qu'une réaction locale aussi minime soit-elle est indispensable à l'obtention de l'immunité. Une expérience de quinze années nous a personnellement convaincus de l'exactitude de cette constatation.

Malheureusement, il est impossible avec une souche de virulence connue, de prévoir l'intensité de la rénction. Fn effet, la susceptibilité raciale ef individuelle des animaux est très variable particulièrement dans l'Ouest-Africain, où du zébu maure, moins sensible, au n'dama de Guinée on trouve toutes les nuances de réceptivité.

\section{RECHERCHES SUR UNE NOUVELLE VOIE D'IMMUNISATION}

En 1955, au cours d'expériences qui' avaient pour principal objet la reproduction de la péripneumonie sous sa forme naturelle, et à la suite d'observations nouvelles et de résultats concordants soigneusement vérifiés, nous avons donné une orientation différente à nos recherches.

En effet, nous constatons l'innocuité relative selon la race d'injections, dans le mufle, de lymphe dont la virulence est contrôlée par inoculations sous-cutanées sur des animaux sensibles. De faibles réactions ont été observées sur les zébus de Mauritanie, tandis que les taurins (*), de race n'dama, se montrent plus sensibles. Une immunité solide est constatée et mise en évidence d'une part par l'injection classique de culture virulente et, d'autre part, par les contrôles sérologiques de la fixation du complément et dé, la séro-agglutination rapide sur lame.

Nous écrivions dès 1955 (12):

«Les inoculations dans le mufle chez les taurins réceptifs, 'si elles confèrent une immunité solide ne sont donc pas aussi inoffensives que chez les zébus. Peut-être des cultures peu virulentes ou l'inoculation de sérosité en suspension plus faible... permettront-elles d'immuniser. les animaux sans réactions fâcheuses ».

Pour confirmer cette hypothèse, nous avons procédé depuis. cette époque à de nombreuses

(*) Dans l'Ouest-Africain d'expression française, on désigne par le lerme de laurins les bœufs sans bosse (Bos taurus) par opposition au zébus (Bos indicus). 
expériences au laboratoire et dans différents territoires de l'Ouest-Africain, sur des animaux de race et de régions différentes (zébus et taurins). en utilisant d'abord la lymphe primaire ou secondaire, puis certains virus-vaccins attérues à des degrés divers.

Nous n'avons pas cru, jusqu'à présent, devoir publier nos résultats avant que cette technicue n'ait donné, entre nos mains, et sur un nomicre suffisant d'animaux, les preuves contrôlées d'efficacité et surtout d'innocuité pour les diverses races de bovins composant le cheptel des régions sahéliennes et guinéennes.

Nous avons ainsi agi avec prudence ef suli la ligne de conduite tracée d'ailleurs par l'O M. 5 . et précisée dans la recommandation suiver.e (Rome 1953) :

« II ne faut en aucun cas déclencher une campagne de vaccination avant de réunir des prelves suffisantes quant à l'innocuité, à l'efficacité ces méthodes vaccinales et quant au degré ef $\bar{c}$ ic durée de l'immunité qu'elles peuvent conférer:

\section{Inoculation de lymphe virulente}

Après nos premières observations qui remo-:tent à 1955, l'objet essentiel de notre expérime- tation est de rechercher le lieu et la techniq.e d'inoculation qui seraient susceptibles d'assirer une innocuité totale aux inoculations de souches virulentes en vue d'une immunisation plus sîre.

Nous nous proposons donc, en fait, de recour:r à la méthode willemsienne en pratiquant les inoculations dans des tissus qui se montrent relativement « indifférents » à l'action pathogère ce M. mycoides.

C'est pourquoi nous avons utilisé, en premier lieu, les inoculations de sérosité virulente pire ou associée à des adjuvarts (lanoline, et gel d'alimine) sur les zébus et les taurins.

Tous les animaux d'expérience ont fait locje; :

- d'examens sérologiques avant inosiction et au cours de l'observation (sero-agclutination rapide sur lame et fixation du complémert) :

- d'examens sémiologiques journaliers ciec prise de temperature :

- d'inoculation d'épreuve.

Au laboratoire, 75 zébus de Mauritanie, 75 métis zébus-taurins du Sénégal et 30 taurins de Guinée ont été inoculés avec du matériel virulent.
Ai cours des premières expériences l'inoculation esł pratiquée sur les zébus de Mauritanie, dans la profondeur du mufle, le plus souvent sans corséquence fâcheuse.

Les doses utılisées ont été au début volontairement élevées : $1 \mathrm{ml}$ de lymphe ou de culture, puis $? \mathrm{ml}$ de produit dilué au $1,50 \mathrm{e}$ puis au $1 / 100 \mathrm{e}$. Enfin, nous avons adopté la dose de $1 / 4$ de $\mathrm{ml}$ de sérosité.

Cependant, les quelques réactions observées nous incitent à modifier cette technique et à contrôler, sur un plus grand nombre d'animaux, l'innocuité totale que nous constatons au laboratoire. après inoculation intra-dermique dans le m.fle.

Cetie expérience est effectuée sur le terrain, à -ore demande, dons la Circonscription d'Ele- age de Kaédi (Mauritanie) (*).

Elle porte sur 50 zébus de race peule, à robe clairc, âgés de 1 à 5 ans, à sćrologic nćgative.

La moitié de ces animaux reçóit $0,25 \mathrm{ml}$ de sérosité lyophilisée dans ia profondeur du mufie. L'autre moitié est inoculée par voie intracermique au niveau du sillon naso-labial. L'innou'té de la voie dermique est confirmée par cette expérience : les 25 zébus inoculés par cette .oie restent totalement indifférents, tandis que des rodules réactionnels n'ayant aucune tendarce à l'extension sont perceptibles sur un certair nombre d'animaux du deuxième lot. D'cutre part, les uns et les autres résistent également à l'inoculation d'épreuve.

Mais l'innocuité totale que nous constatons po _ r es zébus immunisés par cette voie, se révèle $c$ 'scge assez dangereuse pour les taurins: ia ci-tsion accidentelle du germe dans le muscle 0 : e conionctif lâche sous-jacent entraîne des césordres rés graves. Aussi nous avons pensé à reprendre la technique décrite par GIRARD ( 338 ; (13) qui, s'inspirantdes travauxde RAMON, ¿ mo-tré dans une première note, les avantages poss"zles des inoculations de sérosité pleurale erropée dans la lanoline. Cependant, après MORVET (1939) (15), il reconnaît (14) que cette méthoce ne présente pas toutes les garanties c'moc jiré désirables, et se voit dans l'obligation de ic modifier (1942) (16).

*) Nous remercions notre confrère S. BERTRAND d'avoir bier, voulu effectuer cette expérimentation dans des. conditions particulièrement difficiles. 
Nous avons supposé qu'en associant les propriétés bien connues des adjuvants de l'immunité aux possibilités offertes par l'inoculation intradermique dans le mufle, nous pouvions obtenir de meilleurs résullals.

\section{Inoculation de matériel virulent associé à certains adjuvants}

10 taurins e 10 zébus, non immunisés, à sérologie négative, sont inoculés par voie intra-dermique dans le mufle avec $0,25 \mathrm{ml}$ de lymphe enrobée soit dans un mélange de lanoline et d'huile de paraffine, soit dans du gel d'alumine.

Les réactions générales et locales sont très précoces et, d'emblée, très graves. La température dépasse $41^{\circ}$ le matin. Dès le 10 e jour, la gravité des symptômes, l'importance des cedèmes et des réactions ganglionnaires ne laissent aucun doute sur les résultats de cette expérience. En conséquence, tous les animaux sont traités par injection intra-veineuse de 3 grammes de novarsénobenzol qui doit être renouvelée pour arrêter l'évolution de la péripneumonie expérimentale.

II est done évident que l'adjonction d'adjuvant à $M$. mycoides, inoculé par voie dermique, a eu pour conséquence immédiate de favoriser et même d'exacerber le développement du phénomène de WILLEMS, plus encore, peut-être, que par voie sous-cutanée.

Cette expérience a apporté une preuve supplémentaire à la contre-indication de l'emploi des adjuvants dans l'immunisation avec des souches virulentes, comme l'ont démontré MORNET (15) et PHILIPPE (17). Elle a eu pour nous le mérite de confirmer nos hypothèses sur le rôle joué par le derme dans l'établissement de l'immunité.

\section{Utilisation de différents vaccins}

Les résultats obtenus après inoculation de lymphe virulente chez les taurins; même par voie intra-dermique dans le mufle, n'ayant pas donné des garanties suffisantes, nous nous sommes orientés vers l'emploi de virus-vaccins (*) atténués à des degrés divers.

(*) Nous employons le terme de virus-vaccins dans le sens de «germes microbiens atténués 》 devenus vaccinaux. M. mycoides tenant par certains caractères à la fois des virus (ultra-virus) et des microbes, on nous permettra d'utiliser cette expression commode mais réservée mainienant par l'usage aux ultra-virus modifiés.
En effet, comme nous le signalons par ailleurs, dès 1955 (18) notre but essentiel vise à l'immunisation des taurins des différentes régions de l'OuestAfricain. En raison de leur grande sensibilité raciule ef individuelle et des réactions consécutives à l'inoculation sous-cutanée de souches vaccinales, même très atténuées, la protection de ces animaux est particulièrement délicate et reste notre principale préoccupation.

Au contraire, l'immunisation des zébus de la zone sahélienne de Mauritanie, du Sénégal, du Soudan ne présente, à notre avis, aucune difficulté. Leur résistance naturelle permet l'emploi de souches suffisamment virulentes pour conférer une immunité certaine, sans encourir les risques de réactions trop graves qui seraient d'ailleurs un inconvénient mineur pour les éleveurs de ces régions prațiquant eux-mêmes les inoculations virulentes et que n'effrayent pas des réactions, mêmes sérieuses, toujours plus bénignes que celles obtenues par eux.

En conséquence, dans une deuxième série d'expériences, nous utilisons uniquement le taurin sur lequel nous expérimentons;

— des vaccins-cultures de virulence différente ;

- la souche murinisée de 8 e passage selon la technique du Dr GERLACH ;

- les vaccins avianisés préparés à partir des souches T1**, T3** et DK1***.

Comme précédemment, les animaux font l'objet des examens sérologiques et sémiologiques habituels, puis sont soumis aux inoculations d'épreuve.

235 taurins du Sénégal et de Guinée ont été inoculés.

Après nous être assurés de l'innocuité constante et de l'efficacité de l'inoculation par voie intra-dermique par l'emploi de vaccins-cultures et de la souche murinisée, nous avons recherché les avantages que cette voie d'immunisation pouvait présenter sur les méthodes d'inoculation classiques.

(**) Nous remercions MM. PIERCY et KNIGHT d'avoir bien voulu nous faire parvenir en 1955, les souches $T 1$ et T3 du laboratoire de Muguga (Kenya), et de nous avoir communiqué les renseignements qui nous furent particulièrement utiles.

(***) La souche DK1 est une souche de Mycoplasma mycoides, isolée au Sénégal d'un cas naturel de péripneumonie bovine, adaptée et cultivée sur œuf embryonné. Elle s'est révélée immunigène et déjà suffisamment atténuée pour les zébus. 


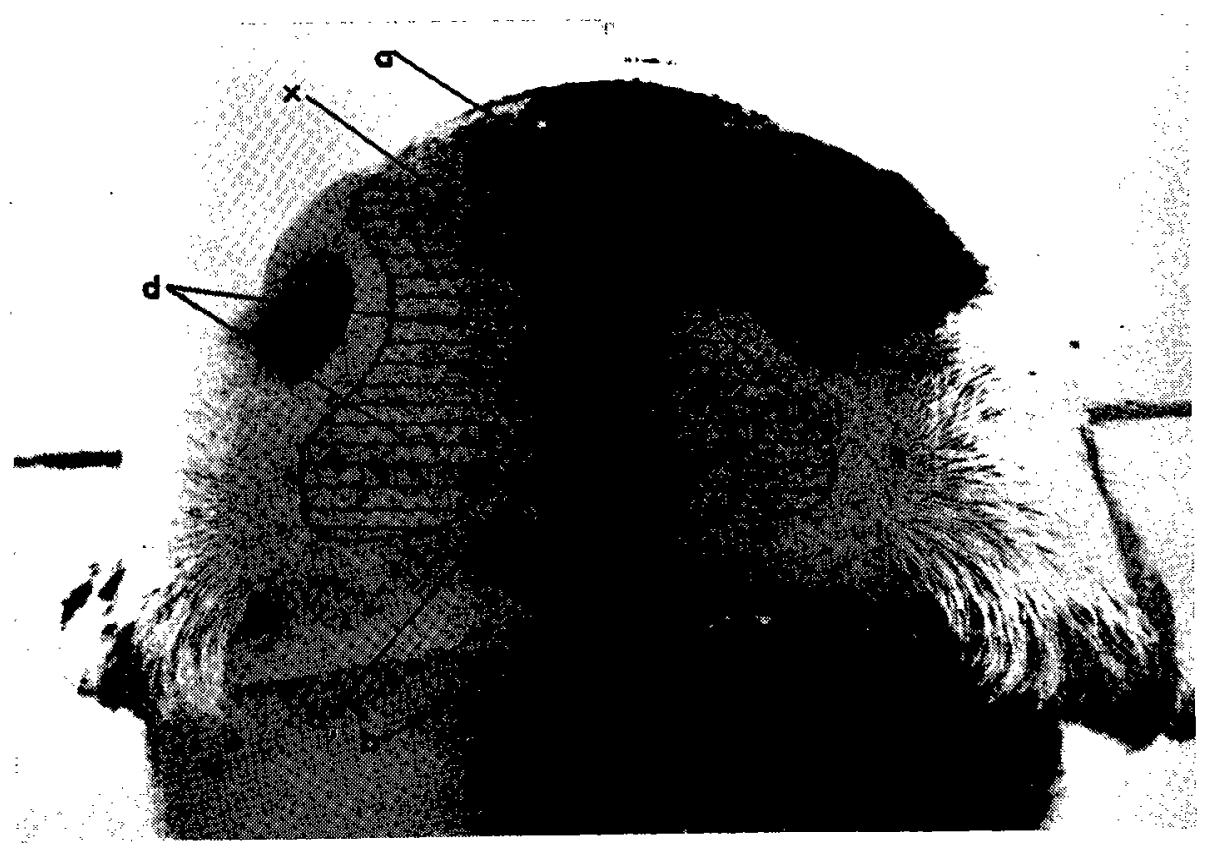

Figure 1. - Mufle vu de face.

$a=$ zones où la région moyenne de conjonctif lâche est développée; $b=$ sillon naso-labial ; $c=$ bord ¥ibre de la lèvre supérieure ; $d=$ zones d'insertion du faisceau moyen du muscle incisif ; $x=$ lieu d'inocuHation recommandé.

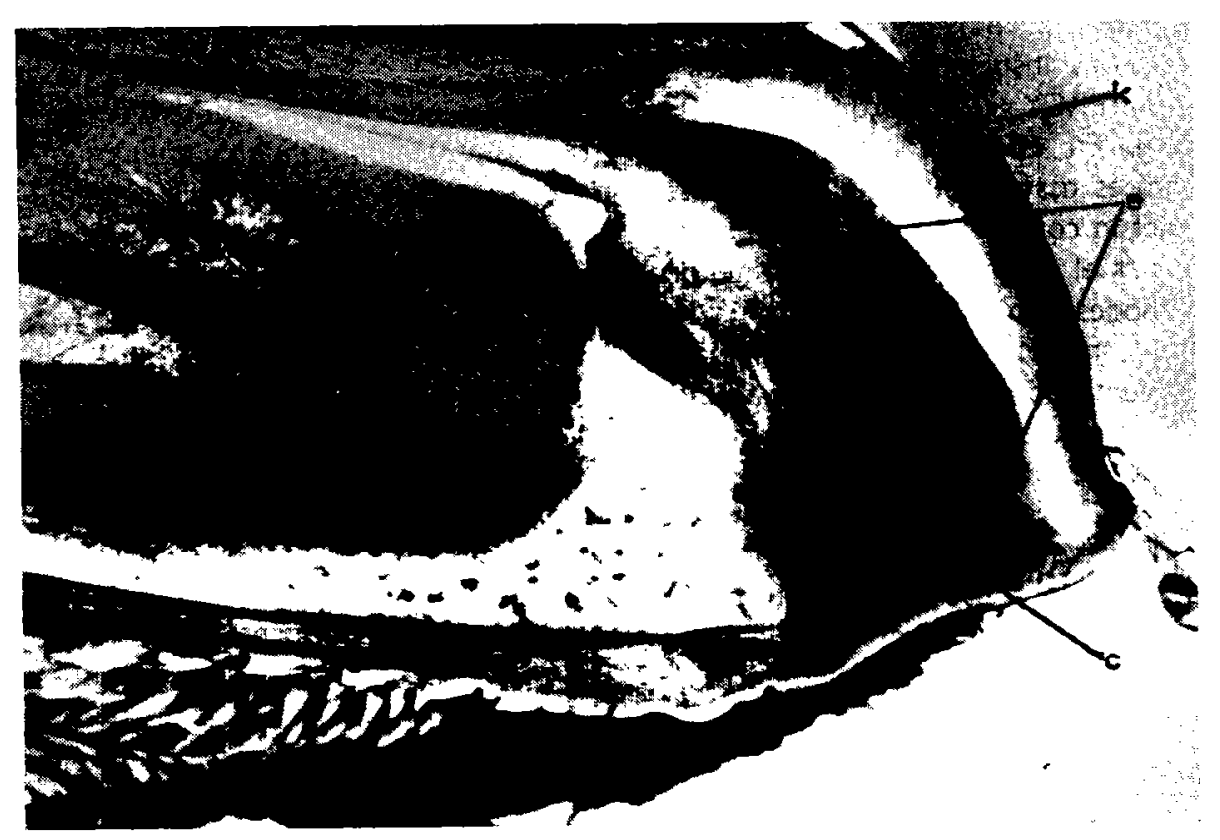

Fig. 2. - Coupe sagiita.e du mufle a nivecu du s."lon rasc-lacal. Mise en évidence des différentes régions, en particulier des zones à conjonctif très iâche.

$k=$ région superficielle (derme - éziderme; ; $e=$ régiar movenne (conjonctif lâche) ; ć = région profonde (faisceau médian du muscle incisif). 


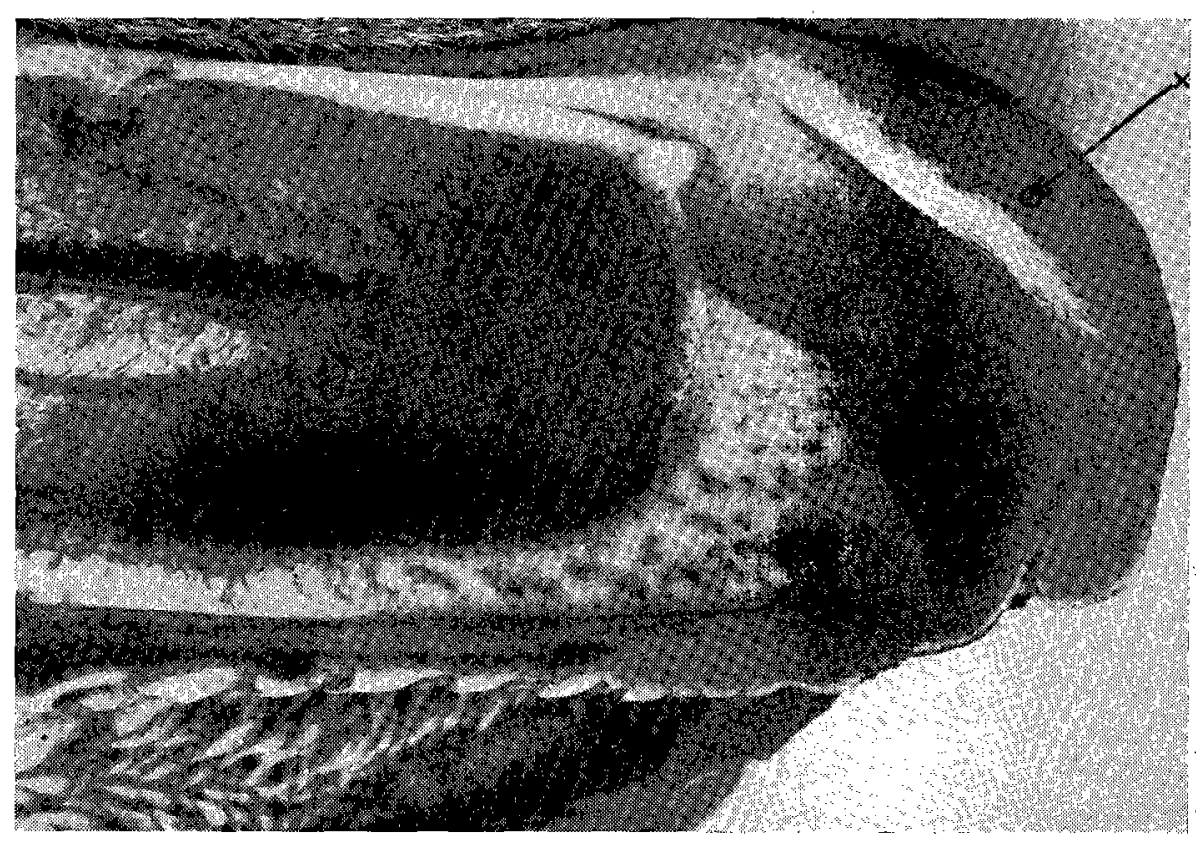

Fig. 3. - Coupe sagittale du mufle au niveau du sillon naso-labial. $x=$ lieu d'inoculation recommandé.

Pour la désignation des différentes régions, sa rapporter à la figure no 2 .

Dans ce but, nous avons alors utilisé les vaccins avianisés lyophilisés tout en poursuivant les recherches sur leur préparation ef leur condition d'emploi, en nous inspirant des techniques de SHERIFF et PIERCY (9), et de PIERCY et KNIGHT (10). En 'effet, la lyophilisation des vaccins avianisés assure leur meilleure conservation, permet la constifution de lots importants plus homogènes et contribue ainsi à l'amélioration des mélhodes prophylacliques.

La souche $T 1$, trop atténuée et nón immunigène a été rapidement abandonnée. La souche DK1, obtenue récemment, est encore en cours d'atténuation et soumise aux tests de contrôle indispensables.

La souche T3 a donc fait l'objet des expérimentations les plus nombreuses. Elle s'est révélée, entre nos mains, suffisamment atténuée pour pouvoir être utilisée par voie intra-dermique chez le taurin.

En 1958 et en 1959, plusieurs lots de vaccins préparés à partir de cette souche, se sont révélés particulièrement efficaces.

Les expériences sont effectuées comme précédemment au laboratoire et dans différents territoires de l'Ouest-Africain.
Au laboratoire, 90 taurins du Sénégal et de Guinée sont inoculés, soit en intra-dermique dans le mufle, soit dans le conjonctif lâche souscutané de la région costale, avec les mêmes lots de vaccin el aux mêmes dilulions afin de comparer valablement les deux techniques:

Des études comparatives identiques sont menées en Haute Volta $\left(^{*}\right)$, au Soudan $\left(^{*}\right)$, au Sénégal (*) de 1856 à 1959, sur des taurinis de provenances diverses.

A Ouagadougou (Haute Volta), la souche T1 (44e passage) se révèle trop atténuée et non immunigène. Nous n'ávons donc pu tirer aucune conclusion valable des résultats obtenus.

Au Centre Fédéral de Recherches Zootech niques de Sotuba (Soudan) (*), pour compléter des résultats précédents (Circonscription d'Elevage de Bamako et de Bougouni (Soudan) (1958), un titrage in vivo du lot no 2-59 de la souche T3

(*) Nous remercions nos confrères R. BALAY qui assumait alors les fonctions de Chef de Service de l'Elevage de la Haute Volta, J. PAGOT, Directeur du C. F. R. Z. de Sotuba ef E. PERRIN, Chef de la Circonscription d'Elevage de Thiès, de l'aide qu'ils ont bien voulu nous apporter. 


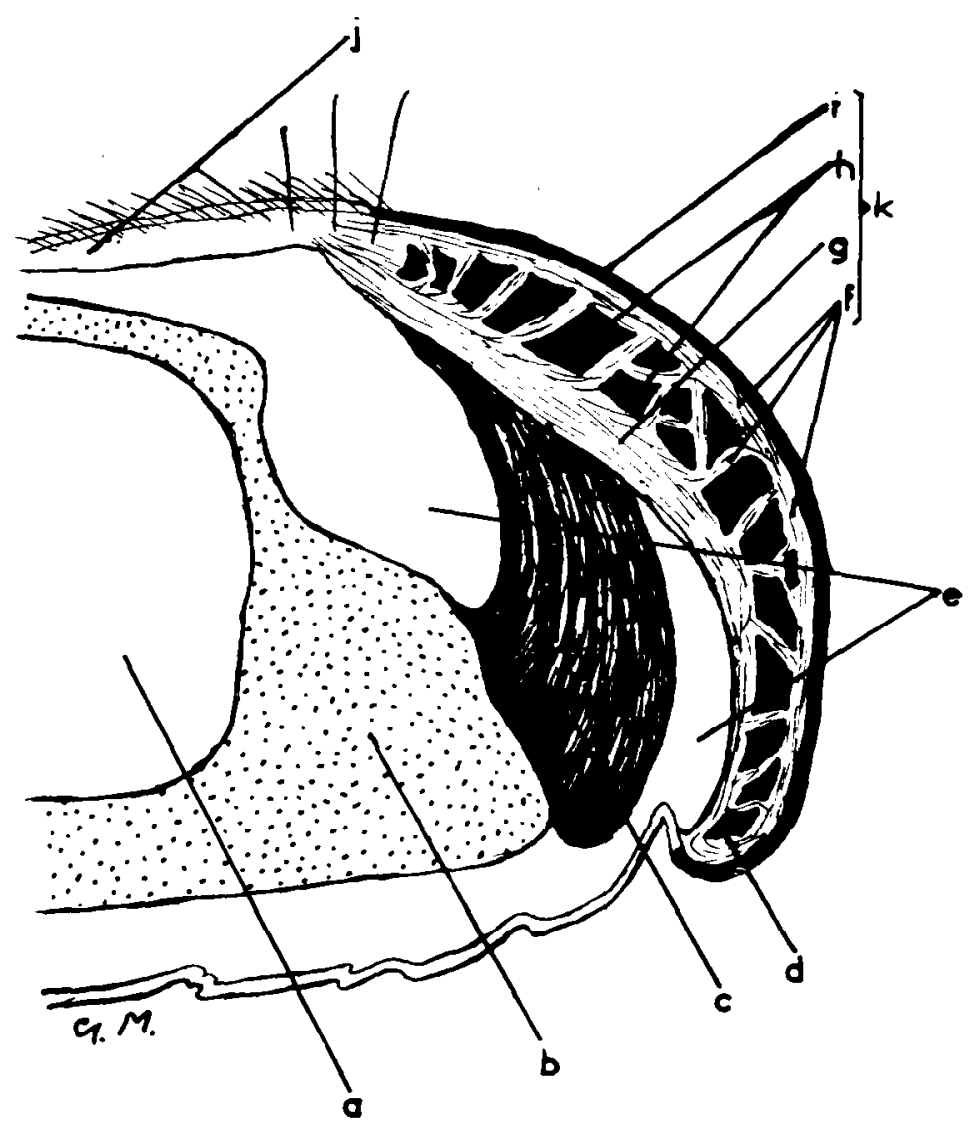

Fig. 4. - Coupe sagittale du mufle cu niveau du sillon naso-labial.

$a=$ pituitaire $; b=$ cartilage de la parai médiane des cavités nasales $; c=$ muscle incisif (région profonde); $d$ - lèvre supérieure ; $e=$ zones de conjorctif lêche (région moyenne) ; $f$ - conjonctif dense : $g=$ faisceaux tendineux du releveur propre de la lèvre sujérieure $; \mathrm{h}=$ glandes naso-labiales $; \mathrm{i}==$ épiderme $; j=$ peau $; k=$ épiderme + derme (région susericielle:

(13e passage sur vitellus) est effectué sur un troupeau de bovins n'dama.

26 taurins choisis dans 4 lots d'animaux inoculés avec des dilutions variables de vaccin avianisé soit sur la côte, soit dans le mufle ont fait l'objet d'examens sérologiques et sémiologiques.

Les résultats confirment :

- que la dose minima vaccinale pour le io: no 2-59 de la souche $T 3$ est de $1 \mathrm{ml}$ d'une dilution au $1: 100$ e d'œuf toial:

- que la voie intra-dermique du mufle est d'une innocuité certaine pour les taurins avec une souche vaccinale, et d'une efficacité supérieure à la voie sous-cutanée.

A Thiès et à Sangalcam (Sénégal), une expérience analogue mais avec un vaccin moins dilué est réalisée avec le lot $n^{\circ}$ 4-59 de la même soliche, sur les taurins n'dama provenant du cercie de Labé (Guinée).

Les résultats concordant avec ceux des expériences précédentes sont consignés dans le tableas ci-apres.

\section{TECHNIQUE DE L'INOCULATION INTRA-DERMIQUE DANS LE MUFLE}

\section{Rappel anatomique}

Cnez les bovins, on désigne sous le nom de mufle (fig. 1) la région totalement dépourvue de poils prolongeant vers le haut la lèvre supériecure entre et dans les naseaux, constituée par ure large surface mamelonnée, diversement 
EXPÉRIMENTATION DION VACCIN AVIANISÉ (souche $T_{3}$ )

Résultats comparatifs entre les voie intra-dermique (I.D.) et sous-cutanée (S.C.)

TABLEAU 1

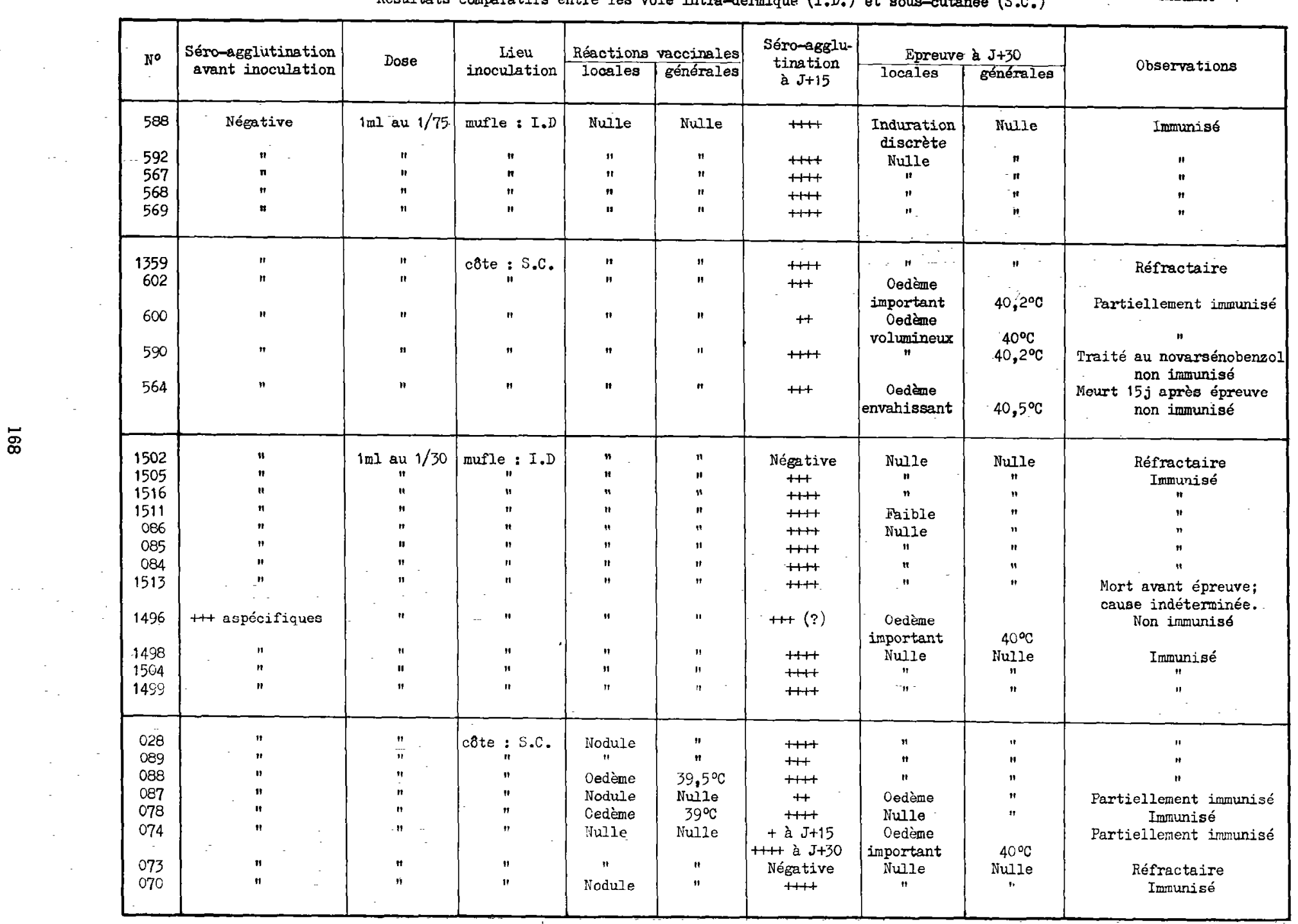


pigmentée, légèrement déprimée en gouttière sur la ligne médiane, par le sillon naso-labial.

D'avant en arrière, il se compose :

- d'une région superficielle (fig. 2 et 4-k) comprenant l'épiderme et le derme sur lequel viennent s'insérer les muscles mobilisateurs de la lèvre supérieure et du mufle.

- d'une région moyenne (fig. 2 et 4-e) discontinue essentiellement composée d'un tissu conjonctif lôche : ef $4-c)$.

- d'une région profonde musculaire (fig. 2

La région superficielle est caractérisée par un épiderme toujours humide sur l'animal en bonne santé et divisé par de petits sillons, en surfaces polygonales, au centre de chacune desquelles s'ouvre le pore d'une glande naso-labiale.

Le derme (*) (fig. 4 et $5-h+g+f$ ) dont l'épaisseur particulièrement importante atteint, par endroit, plus d'un centimètre, englobe entre deux couches de conjonctif très dense (fig. 4-f) l'une superficielle, l'autre profonde, des glandes tubulo-acineuses (fig. 4-h) multi-lobulaires de type salivaires pour les uns (ELLENBERGER, 1911)(20) et sudoripares pour les autres (BOURDELLE ef BRESSOU) (21).

Des travées de conjonctif dense, prenant naissance sur la couche profonde, cloisonnent cette partie glanduleuse et viennent s'insérer sur la couche superficielle donnant à l'ensemble une structure dense et compacte.

Sur la face profonde du derme, dans la zone médiane (fig. 4 ef $5-g$ ) correspondant au sillon naso-labial, on note un épaississement fibreux et nacré, constitué par les terminaisons du tendon du releveur de la lèvre supérieure et par quelques faisceaux tendineux de l'extrémité de la branche supérieure du muscle canin.

La région antérieure est, de plus, caractérisée par une vascularisation sanguine importante (MACKIE ef NISBET 1959) (22) et, certainement. par un réseau lympathique dense, comme le laissent supposer les travaux de ROUVIERE (1932) (23).

La région profonde (fig. 2 ef $4-c$ ) es* corstituee

(*) Pour nous, le derme est le tégument, qui, au point de vue anatomo-physiologique. comprend le derme ces histologistes et une partie de l'hypoderme (pannicule et fascia superficialis). Comme THIÉRY (19) nous le distinguons ainsi du tissu conjonctif sous-cutané dont les ionctions et les propriétés sont neftement différentes. essentiellement par le faisceau médian du muscle incisif. D'une part, ce muscle s'insère sur le bord libre antérieur des os intermaxillaires et sur une partie de l'expansion antérieure du cartilage de la cloison médiane des cavités nasales. D'autre part après s'être infléchi de bas en haut, et d'arrière en avant, il vient se terminer dans la profondeur du derme par des myofibrilles (fig. 5-e) qui s'insinuent entre les éléments glandulaires pour se fixer sur la couche de conjonctif superficiel, de part et d'autre du raphé médian (fig. 4 et $5-g$ ), sur le pourtour interne des naseaux (fig. 1-d).

La région moyenne est constituée par un conjonctif particulièrement lâche (fig. 2-4 et 6-e) qui assure au mufle une grande mobilité. Cette couche conjonctive, bien développée dans les parties supérieures et inférieures (fig. 1-a) est interrompue, dans la partie médiane, par le passage des faisceaux du muscle incisif.

\section{Lieu d'élection de l'inoculation}

Les observations effectuées au cours de nombreuses inoculations d'une part, étayées par les données anatomique d'autre part, nous ont Dermis de définir avec précision le lieu où l'injection doit être effectuée pour éviter les accidents de vaccination sur des animaux très sensibles.

II se sifue à l'intersection du sillon naso-labial, et de la ligne horizontale virfuelle reliant l'angle interne des naseaux (fig. 1 et 3-x).

L'injection est effectuée à une profondeur de 5 à 10 millimètres, c'est-à-dire, dans l'épaisseur du derme (fig. 3-x).

L'injection est effectuée à une profondeur de 5 à 10 millimètres, c'est-à-dire, dans l'épaisseur du derme (fig. 3-x).

Cette technique évite la diffusion du germe toujours dangereuse pour les an imaux très réceptifs soit dans le conjonctif lâche sous-jacent, soit dans les faisceaux du muscle incisif.

Il est important de noter que le caractère du *.ssu particulièrement dense dans lequel l'injection est faite rend cette opération relativement malcisée. Aussi il est recommandé de la pratiquer cvec une seringue robuste, à piston rodé, sur laquelle les aiguilles de type intra-dermique (10-7:10e) peuvent être fixées, soit par un verrou, soit per un pas de vis. 


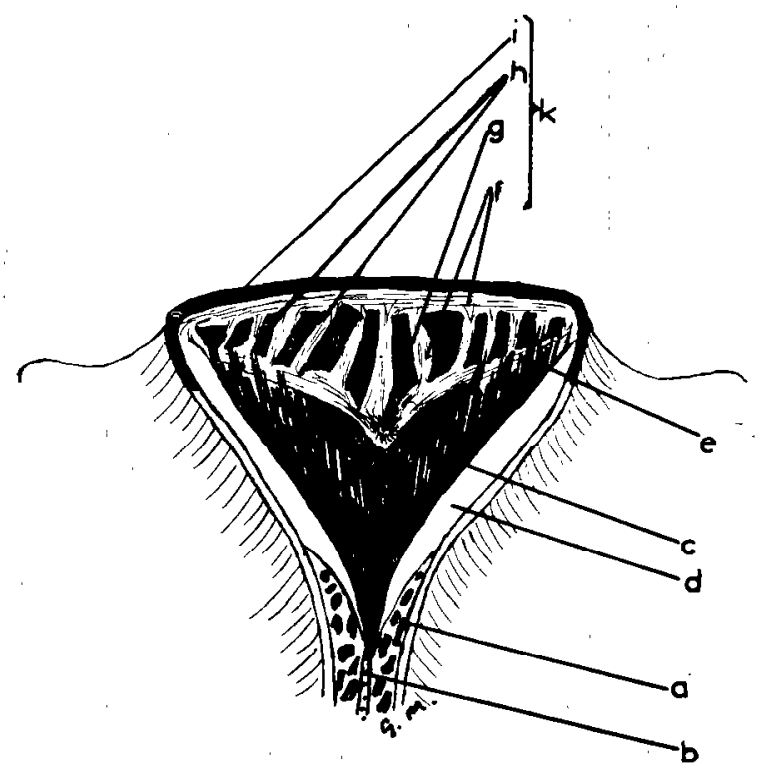

Fig. 5. - Schéma d'une coupe horizontale du mufle au niveau de la ligne reliant l'angle interne des naseaux.

$a=$ glandes naso-labiales $; b=$ cartilage de la paroi médiane des cavités nasales $; c=$ muscle insicif (région profonde) $d=$ conjonctif lardacé $; e=$ zone d'insertion du muscle incisif sur le conjonctif dense du derme ; $f=$ conjonctif dense $; g=$ faisceaux tendineux du releveur propre de la lèvre supérieure : $h=$ glandes naso-labiales $; i=$ épiderme $; k=$ épiderme + derme (région superficielle)

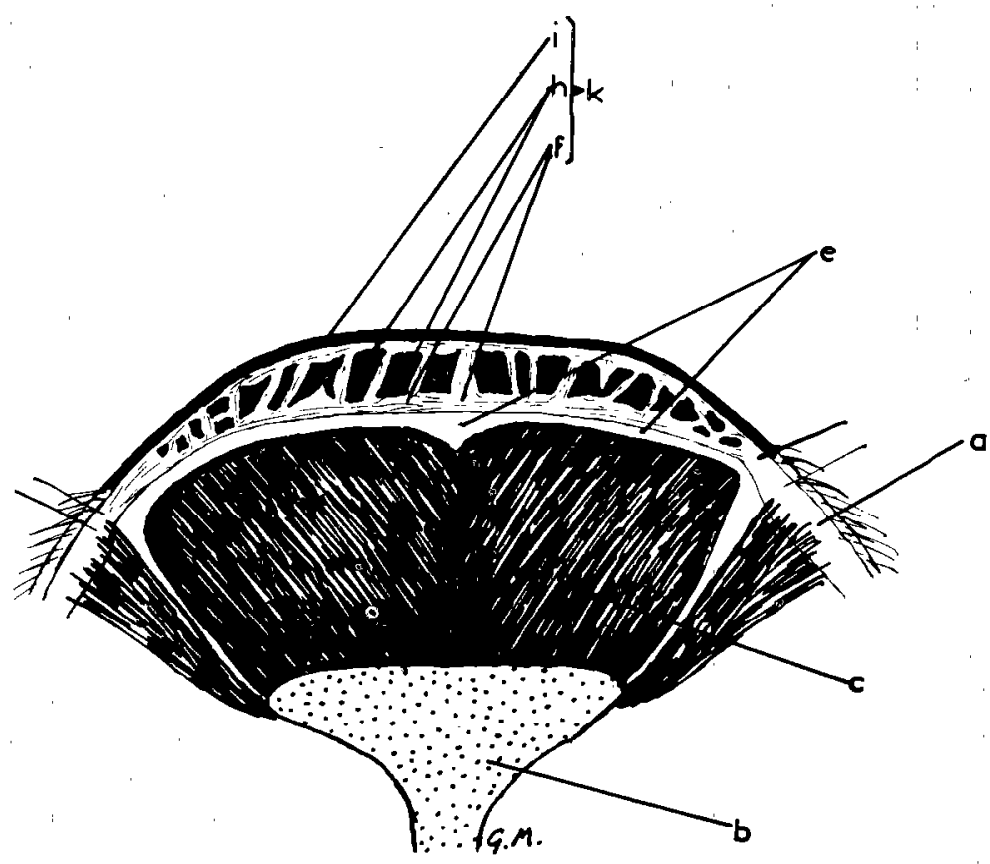

Fig. 6. - Schéma de la coupe horizontale du mufle à $1 \mathrm{~cm} 1 / 2 \mathrm{du}$ bord libre de la lèvre supérieure.

$a=$ peau $; b-$ expansion cartilagineuse de la paroi médiane des cavités nasales ; $c=$ 'muscle incisif (région profonde) $\mathrm{e}=$ conjonctif lâche (région moyenne) $f=$ conjonctif dense $; \mathrm{h}=$ glandes nasolabiales $; \mathrm{i}=$ épiderme $; \mathrm{k}=$ épiderme + derme (région superficielle). 
absolve, pour obtenir l'innocuité, « d'amener sûrement le liquide au niveau du tissu conjonctif sous-cutané ».

Ces caractères anatomiques et physiologiques qui sont plus particulièrement marqués au niveau du mufle se retrouvent, avec plus ou moins de netteté, dans tout le derme du revêtement cutané. Aussi expérimentons-nous un autre lieu d'élection donnant, pour ces raisons, des résultats identiques mais qui doit faciliter l'injection vaccinale.

La vérification de ces différentes hypothèses a déjà fait l'objet d'un important travail dont les résultats scront publićs ultćricurement.

\section{CONCLUSION}

- Après avoir rappelé les différentes techniques vaccinales contre la péripneumonie bovine, l'innocuité relative de f'injection de lymphe virulente dans le mufle des zébus suivie de l'établissement d'une immunité certaine est démontrée.

- Mais la susceptibilité particulière des bœufs sans bosse de l'Ouest-Africain interdit la généralisation de cette méthode vaccinale. L'emploi de virus-vaccin esł donc envisagé.

- Le lieu d'inoculation est. précisé ainsi que la technique opératoire.

- La posssibilité d'utiliser des virus-vaccins dont le faible degré d'atténuation interdit leur emploi par voie sous-cutanée est mise en évidence.

- Les avantages de ce nouveau mode d'immunisation (innocuité - efficacité accrue - rapidité d'apparition de l'immunité) sont démontrés.

- Iis ne sont pas la conséquence de propriétés anatomo-physiologiques particulières du mufle, mais de celles du derme en général, associées au lymphotropisme de Mycoplasma mycoides.

Laboratoire central de l'Elevage

« Georges Curasson 》

Directeur : P. MORNET.

\section{BIBLIOGRAPHIE}

1. WILLEMS (L.). - Mémoire sur la pleuropneumonie enzootique du groś bétail. Rec. Méd vét., 1852, $28: 401$.

2. HALL (G. N.), BEATON' (W. "G.). - Infectiosity of the blood in the case of natural and experimental bovine pleuro-pneumonia. J. comp Path., 1931, $44: 170$.

3. TURNER (A. W.), CAMPBELL (A. D.) et $\operatorname{DICK}(A . T$. ) - Recents works about contagious bovine pleuro-pneumonia in North Queensland. Aust. Vet. J., 1935; 71 : 63.

4. MORNET (P.), ORUE (J.) et DIAGNE (L.). Etude du phénomène de Willems dans la péripneumonie bovine. Bull. Serv. El. Ind. ani., A. O. F., 1949, $2: 2$.

5. CURASSON (G.), HANRAS, - Un vaccin contre la péripneumonie bovine. Bull. Acad. vét. France, 1930, 3, 95.

6. MARTINS-MENDES (A.). - Subsido para o estudo da peripneumonia contagiosa dos Bovinos em Angola. Junta de investigacoes do Ultramar, Ministerio do Uitramar. Lisboa, 1958 : 175.

7. WALKER (J.). - Experiments and observations in connection with « pleuro-pneumonia confagiosa bovum $\gg$ and preventive method of inoculation. Dept agr. Kenya colony Bull., 1921, $2: 175$.

8. WALKER (J.). - Pleuro-pneumonia, pure culture vaccine inoculation experiments. Dept Agri. Kenya Bull., 1922, 3 : 85.

9. SHERIFF (D.), PIERCY (S. E.). - Experiments with an avianised strain of the organism of confagious bovine pleuropneumonia, Vet. Rec., 1952, $64: 615$.

10. PIERCY (S. E.), KNIGHT (G. J.). - Correspondance personnelle, 16 sept. 1955.

11. PIERCY (S. E.), KNIGHT (G. J.). - Studies with avianised strains of the organism of contagious bovine pleuro-pneumonia. Vet. Rec., 1956, $68: 367$.

12. ORUE (J.). - Rapportannuel (microbiologie). Laboratoire Central de l'Élevage « Georges Curasson », Dakar, 1955, p. 83.

13. GIRARD (H.): - Essai de vaccination contre la péripneumonie à l'aide de la sérosité pleurale incorporée dans la lanoline. C. $R$. Soc. Biol., 1938, $129: 590$.

14. GIRARD $(H$.$) . - Nouvelle tentative de vacci-$ nation contre la péripneumonie à l'aide de la sérosité pleurale incorporée dans la lanoline. C. R. Soc.' Biol., 1939, I30: 590.

15. MORNET (P.). - Essai d'immunisation contre la péripneumonie par la sérosité enrobée en excipient gras. Bull. Serv. Zoot. Epiz. A. O. F., $1939,3: 12$. 
16. GIRARD $(H$.$) . - De la vaccination en ma-$ tière de péripneumonie bovine. Bull. Soc. Path. ex., 1942, $35: 80$.

17. PHILIPPE (J.). - Travaux de recherches effectuées par le Laboratoire de Recherches de Bamako (Soudan). Bull, Serv. Zoot. Epiz. A. O.F. 1939, 2 (4) : 76.

18. ORUE (J.). - Rapport annuel (Microbiologie), Laboratoire Central de l'Élevage « Georges Curasson 》, Dakar, 1955, p. 82.

19. THIERY (G.). - Note sur I'histologie du mufle des bovidés de l'Ouest africain. Rev. Elev. Méd. vét. Pays trop. 1960, 13 (2-3) : 155-9

20. ELLENBERGER (W.). - Handbuch der Vergleichenden Mikroskopischen Anatomie der Haustiere, Berlin, Parey Edit., 1911. 1 re édit., p. 45.

21. BOURDELLE (E.), BRESSOU (C.). - Anatomie régionale des animaux domestiques. Paris, Baillière édit., 1920.

22. MACKIE (A. M.) et NISBET (A. M). - The histology of the bovine muzzle J. agr, Sct. G. B., 1959, $52: 376$.

23. ROUVIERE $(H$.$) . - Anatomie des lympha-$ tiques de l'homme. Paris, Masson et Cie, 1932.
24. PROVOST (A.). - Communication personnelle, Laboratoire de Farcha, Fort Lamy (Tchad), 1957.

25. PECAUD (G.). - Cité par CURASSON (G.) in Traité de Pathologie exatique vétérinaire et comparée, Paris, Vigot Frères édit., 1942, 2e édit., p. 331.

26. ALDIGE (E.). - Notice sur la péripneumonie contagieuse des bovidés en A. O. F., Gorée, Imp. Gouvt général A. O. F., 1917, p. 44.

27. CURASSON (G.). Traité de Pathologie exotique vétérinaire et comparée, Paris, Vigoł Frères édit., 1942, 2e édit., p. 331-332.

28. POLIBARD (A.). - Précis d'histologie physiologique, Paris, Doin et Cie édit. 1950, 5 édit., p. 600.

Cet article était rédigé lorsque nous avons eu connaissance du travail de A. Provost, J. M. Villemot et $R$. Queval intifulé « Recherches immunologiques sur la péripneumonie. VII. Immunisation au moyen d'une souche avianisée de Mycoplasma mycoides var. mycoides inoculée par voie du mufle. 》 paru dans cette même revue, 1960, 12 (4) : 381 , el qui fera l'objet de discussions dans des rotes ultérieures.

\begin{abstract}
SUMMARY
Contagious Bovine Pleuropneumonia. Details of a new method of immunisation, the results obtained and conclusions.
\end{abstract}

Having recapitulated the different techniques in use for immunisation against bovine pleuropneumonia, the relative innocuity of the injection of virulent lymph into the muzzle of Zebu cattle followed by the establishment of an immunity is described.

The special susceptibility of the non-humped breeds of cattle in West Africa, however, precludes the general use of this method with them and a virus-vaccine is therefore essential.

The point of inoculation and technique of administration is described. The possibility of using virus-vaccines only slightly attenuated, by this route is shown and the advantages described. (Innocuity, increasing effect, and rapid appearance of immunity.)

This is not due to the particular anatomo-physiological properties of the muzzle, but to those of the skin in general associated with the lymphotrophism of Mycoplasmo mycoides. 


\section{RESUMEN}

La perineumonia bovina. Sobre una nueva via de immunización. Resultados. Consecuencias e hipótesis

Recuerda lás diferentes técnicas de vacunación contra la perineumonia bovina. Demuestra luego la immunidad eficaz que proporciona la inyección de linfa virulento en el hocico del ganado cebú, técnica que no' es peligrosa.

El ganado sin joroba, muestra una gran sensibilidad para esta técnica, lo que impide su generalización. Se impone, por tanto, el empleo de virus vacuna.

Indica la región de inoculación y la técnica seguida.

Pone en evidencia la imposibilidad de utilizar la via subcutanea en la vacunación con virus vivo débilmente atenuado.

Demuestra las ventajas de este nuevo método de immunizacion (inocuidad, gran eficacia, rapidez en la aparición de la inmuridad).

Dichas ventajas no obedecen a las propiedades anatomofisiológicas particulares del hocico, pero si a las de la dermis en general, asociadas al linfotropismo del Mycoplasma mycoides. 